\title{
The Relationship between Course Construction of English "An Introduction to Linguistics" and Training of Overall Qualities of English Majors
}

\author{
Qing Lu
}

School of Foreign Languages, Agricultural University of Hebei, Baoding, 071001, China

Keywords: English major. An Introduction to Linguistics. overall qualities. critical thinking skills. innovation ability

\begin{abstract}
In light of a general lack of critical thinking skills and innovation ability etc of today's English majors, this paper discusses about the relationship between course construction of linguistics and training of overall qualities of English majors including critical thinking skills and innovation ability from five perspectives of teaching objectives, course characteristics, teaching content, teaching methods and evaluation methods of English course "An Introduction to Linguistics", to make a certain contribution to training and enhancing overall qualities of English majors by further strengthening the construction of linguistics course.
\end{abstract}

\section{Teaching status of English major in current colleges}

With further expansion of China's opening to the outside world, international exchanges and trade become increasingly frequent, and the role and value of English as an international language become increasingly prominent. China has an increasing demand of English talents. To meet requirements of social development, lots of Chinese higher education institutions increase efforts in college English course reform and construction, to strengthen training of students' basic skills including listening, speaking, reading, writing and translating etc and enhance their cross-cultural communication competence. However, although some special skills have been enhanced through training, students' overall qualities are not satisfactory. Overall qualities discussed in this paper include ideological quality, social culture quality, professional quality, rational thinking, critical thinking skills and innovation ability etc. This paper will explore the important role of course An Introduction to Linguistics in training of overall qualities of English majors by discussing about the relationship between teaching objectives, course characteristics, teaching content, teaching methods, course evaluation of this course and training of students' overall qualities respectively.

\section{The relationship between teaching objectives and course characteristics of English "An Introduction to Linguistics" and training of overall qualities of English majors}

English Language and Literature major attaches importance to course An Introduction to Linguistics, which is determined by training objectives and basic requirements of this major. Although teaching programs and teaching plans are not always the same in different colleges, they basically follow provisions specified in English Major Syllabus for Higher Institutions (2005): in the 21st century, English majors in Chinese higher institutions shall have solid basic skills, extensive knowledge, certain professional knowledge, strong ability and high qualities. That is to say, students shall master solid basic skills of English and grasp firmly professional English knowledge, expand humanity knowledge and knowledge of science and technology, master basic knowledge related to future work after graduation, train their ability to acquire knowledge, independent thinking ability and innovation ability, and improve ideological and moral quality, cultural quality and psychological quality. Therefore, English majors shall lay emphasis on training literary accomplishment and rational thinking while strengthening basic language skills and improving a variety of skills. In recent years, however, more and more English experts and teachers find that English majors have not a sound structure of overall qualities, as English majors focus on accumulating vocabulary and 
grammar etc during learning, practicing and improving a certain skill, while ignoring improving social culture quality, rational thinking, critical thinking skills and innovation ability, and there is a general lack of critical thinking skills and innovation ability among English majors.

As a required professional knowledge course of undergraduate English majors, English course "An Introduction to Linguistics" aims at allowing students to know about rich achievements of human language researches, improving their important understanding of language world, humanity, economy, science and technology, and self-cultivation etc, training language awareness, and developing rational thinking. Linguistics course can help expand students' thinking and horizon, train and improve students' overall qualities.

Teaching objectives and course characteristics of English course "An Introduction to Linguistics" comply well with English talents training objectives and requirements specified in the above English Major Syllabus for Higher Institutions. Therefore, in discipline construction and reform of English major, setting and construction of course An Introduction to Linguistics shall be strengthened, in order to train qualified professional English talents.

\section{The relationship between teaching content of English “An Introduction to Linguistics” and training of overall qualities of English majors}

Teaching content of linguistics course mainly includes basic knowledge of linguistics, language analysis and research methods. Teaching materials of this course of Chinese colleges basically cover two parts of content. The first part is microlinguistics including phonetics, phonemics, morphology, syntax, semantics and pragmatics. In short, the nature and law of language are discussed from perspectives of pronunciation, words, sentences, meaning and use. Another part is macrolinguistics including language and society, language and culture, language and thinking, language and cognition, language and computer, language and literature, foreign language teaching etc. In other words, besides discussion about the nature of language, linguistics forms interdisciplines with other disciplines and fields, such as sociolinguistics, psychological linguistics, computer linguistics, corpus linguistics and stylistics etc, to discuss commonly about relations of language with other disciplines, help train students' interdisciplinary awareness, guide students to discover interdisciplinary relations, broaden students' horizon, expand their knowledge, and enhance their connotation and cultivation and social culture quality. As is known, linguistics belongs to social sciences, and is a branch of social sciences with language as research objects. However, a lot of research and analysis methods belonging to natural sciences are used in linguistics researches. Therefore, linguistics course can integrate organically knowledge of social sciences with knowledge and methods of natural sciences, which makes up the lack of students' theory and methods of natural sciences to some extent.

Courses for English majors are divided into three categories, namely skills courses of English major, knowledge courses of English major and knowledge courses of related majors. Skills courses of English major refer to comprehensive training courses and a variety of single training courses of English skills, such as basic English, listening, spoken English, reading, writing, written translation and interpretation etc; knowledge courses of English major refer to courses related to English language, literature and culture, such as English linguistics, English lexicology, English grammar, English stylistics, British and American Literature, British and American society and culture, western cultures etc; and knowledge courses of related majors refer to knowledge courses of other majors related to English, such as diplomacy, economy and trade, law, management, news, education, science and technology, culture and military etc. Learning of theories related to linguistics course is a basic accomplishment that English majors shall have, and is a basis of knowledge and analysis of specific linguistic phenomena. It promotes the first category of professional skills to a theoretical and systematic height to a certain degree, and in turn guides learning and practice of professional skills, such as application of knowledge of phonetics and phonemics in spoken English and listening, and application of knowledge of morphology, syntax, semantics and pragmatics in reading, writing and translation etc; during learning, students could also combine linguistics course with the category of literature and culture courses and the third category of knowledge courses of related majors for 
interdisciplinary learning and research, i.e. analyze linguistic phenomena, language operation and processing involved in different categories with theories and methods of linguistics. Linguistics course can make students realize that theoretical knowledge learned in classroom is not isolated and can be applied to other disciplines or fields. Knowledge can be achieved through comprehensive study, and disciplines are interlinked. Only with a comprehensive knowledge and understanding of content of linguistics course, can a comprehensive, systematic and scientific understanding of language be formed, and thus better master and use language.

\section{The relationship between teaching methods and course evaluation of English "An Introduction to Linguistics” and training of overall qualities of English majors}

As mentioned above, linguistics course is abstract and hard to understand due to lots of profound terminologies and theories. Therefore, teachers shall teach basic, important and representative content, so that students could master basic theoretical knowledge of this course. Basic theoretical knowledge is undoubtedly important. However, if "cramming" teaching method is blindly applied to classroom, on the one hand, students would feel boring and be tired of learning, and on the other hand, teaching objectives of training students' rational thinking and enhancing their critical thinking skills and innovation ability cannot be achieved effectively. Expounding something mechanically shall be avoided in basic theory courses. Theories are the skeleton, and appropriate and vivid linguistic phenomena or examples that explain theories are flesh and blood: with skeleton, flesh and blood, basic theory courses can be alive, organic and attractive (Nie Zhiping, 2012). When teaching other basic and professional knowledge courses, teachers could use consciously some theories and methods in linguistics, and could select and use linguistic phenomena and information of other courses when teaching linguistics, and add timely and fresh typical linguistic examples in daily life appropriately and flexibly, so as to enrich classes, stimulate students' interest in learning, deepen students' linguistic knowledge, enhance their professional quality, and cultivate their ability to observe, analyze and solve problems. Meanwhile, on the premise of guaranteeing main knowledge framework, teachers shall update knowledge so that students could know about development trend of this discipline timely, introduce cutting-edge theories and topics, encourage students to learn independently and selectively according to their interests, and make students develop good habit of independent learning and enhance their self-learning ability.

The author believes that teachers could take flexible and diverse teaching methods according to different content of chapters in classes of An Introduction to Linguistics. For example, before teaching new content, teachers could arrange some problems to think about, and students could think alone or discuss in groups; discuss about an important knowledge point or theory in classes, and extend book content, so that students could have a more profound and deep knowledge and understanding of knowledge; after classes, teachers could assign extended discussion tasks about important knowledge, or guide students to analyze and solve actual problems encountered in language learning or verbal communication with theoretical methods learnt in classes, or encourage students to search materials for reading through library and network etc and complete a paper independently. In short, through discussion and actions, students could change from passive into active, give active play to subjective initiative, participate in and be integrated into classes, and apply consciously knowledge they have learned in classes to actual language use and communication.

Evaluation methods of this course shall not depend overly on closed-book examinations which examine basic concepts and theories. If so, students would memorize mechanically for examinations without critical thinking skills, and thus could not train and enhance their comprehensive analysis ability. Course evaluation can be carried out by multiple tests and comprehensive evaluation, such as closed-book examinations for basic theoretical knowledge, open-book examinations for critical thinking skills and comprehensive explaining ability; course performance can be achieved through completion of short papers and papers at the end of the semester during course learning. The original intention of changing teaching methods and evaluation methods is to change students' learning methods and learning effects, stimulate students' interest in learning, strengthen students' critical 
thinking skills, think about and solve actual problems in language use and communication, establish students' innovative consciousness and encourage students to try innovatively. This will help change the general lack of critical thinking skills of current English majors and weak written language expression ability to some extent.

\section{Conclusions}

A qualified English major graduate shall not only be proficient in basic skills of listening, speaking, reading, writing and translating and professional quality related to social culture, but also develop rational thinking actively, enhance critical thinking skills, expand open and diverse ways of thinking, and strengthen the ability to solve problems innovatively. English course "An Introduction to Linguistics” plays a very important role in training English majors' overall qualities. Linguistics teachers and relevant personnel shall discuss and explore actively about how to help students achieve the above objectives better in this course, promote students achieve greater learning effects and their more comprehensive development, and further strengthen the construction of this course.

\section{References}

[1] Foreign Language Teaching in Colleges and Universities Steering Committee. English Major Syllabus for Higher Institutions [Z]. Beijing, Foreign Language Teaching and Research Press/Shanghai: Shanghai Foreign Language Education Press, 2005

[2] Hu Zhuanglin. Linguistics [M]. Beijing: Peking University Press

[3] Xiong Xueliang. Exploration of Linguistics Teaching for Undergraduates [J]. China University Teaching, 2007, (05).

[4] Ju Yumei. Reflections on the Teaching of Linguistics to English Majors [J]. Foreign Languages and Their Teaching, 2007a, (08).

[5] Zhang Xianliang, Re-reflections on the Content and Methods of "An Introduction to Linguistics"

[J]. China University Teaching, 2010, (02)

[6] Chen Xinren. Discussion on Teaching Methods of "Introduction to General English Linguistics for Undergraduates” [J]. China University Teaching, 2007, (12).

[7] Hu Min, Developing Thinking Ability and Scientific Capability through the Course of Linguistics. Journal of Xiaogan University (Social Sciences Edition), 2000, (05)

[8] Bai Yu, The Re-orientation of English Linguistics Teaching for Undergraduates [J]. Journal of University of International Relations, 2007, (01)

[9] Chen Zeyuan, Zeng Xiaorong. Literature Review of Course “An Introduction to Linguistics” for College English Majors [J]. Journal of Huanggang Normal University, 2012, (02)

[10] Nie Zhiping, Several Problems in Course Construction of An Introduction to Linguistics [J]. Journal of Zhejiang Normal University (Social Sciences), 2012, (02) 